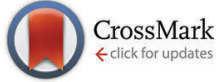

Cite this: J. Mater. Chem. C, 2015, 3, 11228

Received 21st July 2015,

Accepted 24th September 2015

DOI: $10.1039 / \mathrm{c} 5 \mathrm{tc} 02218 \mathrm{e}$

www.rsc.org/MaterialsC

\section{Analysing the effect of the crystal structure on upconversion luminescence in $\mathrm{Yb}^{3+}, \mathrm{Er}^{3+}$-co-doped $\mathrm{NaYF}_{4}$ nanomaterials $\dagger$}

\author{
D. T. Klier $\ddagger$ and M. U. Kumke*
}

$\mathrm{NaYF}_{4}: \mathrm{Yb}$ :Er nanoparticles (UCNP) were synthesized under mild experimental conditions to obtain a pure cubic lattice. Upon annealing at different temperatures up to $T_{\text {an }}=700{ }^{\circ} \mathrm{C}$ phase transitions to the hexagonal phase and back to the cubic phase were induced. The UCNP materials obtained for different $T_{\text {an }}$ were characterized with respect to the lattice phase using standard XRD and Raman spectroscopy as well as steady state and time resolved upconversion luminescence. The standard techniques showed that for the annealing temperature range $300{ }^{\circ} \mathrm{C}<T_{\text {an }}<600{ }^{\circ} \mathrm{C}$ the hexagonal lattice phase was dominant. For $T_{\text {an }}<300{ }^{\circ} \mathrm{C}$ hardly any change in the lattice phase could be deduced, whereas for $T_{\text {an }}>600{ }^{\circ} \mathrm{C}$ a back transfer to the $\alpha$-phase was observed. Complementarily, the luminescence upconversion properties of the annealed UCNP materials were characterized in steady state and time resolved luminescence measurements. Distinct differences in the upconversion luminescence intensity, the spectral intensity distribution and the luminescence decay kinetics were found for the cubic and hexagonal lattice phases, respectively, corroborating the results of the standard analytical techniques used. In laser power dependent measurements of the upconversion luminescence intensity it was found that the green (G1, G2) and red (R) emission of $\mathrm{Er}^{3+}$ showed different effects of $T_{\text {an }}$ on the number of required photons reflecting the differences in the population routes of different energy levels involved. Furthermore, the intensity ratio of $G_{\text {full }} / R$ is highly effected by the laser power only when the $\beta$-phase is present, whereas the G1/G2 intensity ratio is only slightly effected regardless of the crystal phase. Moreover, based on different upconversion luminescence kinetics characteristics of the cubic and hexagonal phase time-resolved area normalized emission spectra (TRANES) proved to be a very sensitive tool to monitor the phase transition between cubic and hexagonal phases. Based on the TRANES analysis it was possible to resolve the lattice phase transition in more detail for $200{ }^{\circ} \mathrm{C}<T_{\text {an }}<300{ }^{\circ} \mathrm{C}$, which was not possible with the standard techniques.

\section{Introduction}

Nanomaterials labeled with fluorescent dyes have been widely used in life-science applications and biological studies. ${ }^{1-6}$ Typically, these labeling compounds are organic dyes, such as Alexa Fluor, fluorescein isothiocyanate (FITC), cyanine dyes (Cy3, Cy5 or Cy7) and rhodamin derivates. ${ }^{7-9}$ Recently, semiconductor quantum dots have emerged as great potential candidates for life-science applications. ${ }^{10-16}$ These conventional down conversion luminescence probes require light in the ultra violet or visible spectral range for excitation. Their main disadvantages are the background-related

University of Potsdam, Department of Chemistry (Physical Chemistry), Karl-Liebknecht-Str. 24-25, 14476 Potsdam, Germany.E-mail: kumke@uni-potsdam.de $\dagger$ Electronic supplementary information (ESI) available: TEM image of UCNP 400 as well as further detailed XRD diffractograms of $\mathrm{UCNP}_{x}$ and crystallite size out of the Debye-Scherrer calculation are shown. See DOI: 10.1039/c5tc02218e

$\$$ These authors equally contributed to this study. auto-fluorescence of biological samples due to the UV/VIS excitation wavelengths typically used, photobleaching of the probes, low light penetration depth in tissues like skin and possible damages to the biological matrix under investigation. ${ }^{1,7,17}$

Upconversion (UC) luminescent materials have attracted great interest in recent years due to their outstanding photophysical properties and the resulting application potentials in various fields such as solid-state lasers, solar cells, color displays or life sciences. ${ }^{18-27}$ Upconversion materials based on lanthanide-doped fluorides received a lot of attention owing to their high UC efficiency and photostability. Highly efficient UC materials among various fluoride based UC phosphors are $\beta$-phase $\mathrm{NaYF}_{4}$ doped with $\mathrm{Yb}^{3+}$ and $\mathrm{Er}^{3+}$ or $\mathrm{Yb}^{3+}$ and $\mathrm{Tm}^{3+}$ as a sensitizer-activator pair, respectively. ${ }^{28-33}$ The luminescence properties of upconversion nanoparticles (UCNP) are dependent on a complex interplay between different dopant ions on the one hand and the host lattice on the other hand..$^{8,9,34}$ Thus, the 
luminescence of these particles can be tuned by the crystal structure of the host lattice, the particle size, the ratio of different lanthanides used as dopants, and the power density of the excitation light. ${ }^{35}$ For example, for $\mathrm{NaYF}_{4}$ the host lattice geometry can be switched by annealing between the cubic $(\alpha)$ and the hexagonal $(\beta)$ phases subsequently also tuning the UC properties of the materials. ${ }^{20,36-39}$

In the present study, the UCNPs were synthesized under mild reaction conditions $\left(T_{\text {synthesis }}=160{ }^{\circ} \mathrm{C}\right)$ in order to obtain a pure cubic $(\alpha)$ phase host lattice. Subsequently, in order to investigate the influence of the crystal phase on the upconversion luminescence properties different annealing temperatures $\left(T_{\mathrm{an}}\right)$ were applied to induce a phase transition in the material. The alterations in the photophysical properties of the UCNP materials obtained for different $T_{\text {an }}$ were monitored using steady state and time-resolved luminescence techniques. Time-resolved area normalized emission spectra (TRANES) can often be a useful method to illustrate the overall dynamics, especially to identify at least two emissive states. ${ }^{40-45}$ Based on the luminescence data the interplay of the population routes of sensitizer and activator electronic states involved in different luminescence upconversion processes was analyzed in order to increase the understanding of the UCNP photophysics. The detailed knowledge of it at a molecular level provides the basis for UCNP material synthesis tailored for the specific needs of applications they are going to be used such as multiplexing applications like temperature sensing or in vivo imaging. The upconversion luminescence data are complemented by Raman, SEM and XRD measurements to determine the size and the crystal phase of the UCNP investigated and to underline the power of luminescence techniques in the structural characterization of such materials.

\section{Experimental}

\subsection{Materials}

All rare earth oxides $\mathrm{RE}_{2} \mathrm{O}_{3}$ (RE: $\mathrm{Y}, \mathrm{Yb}$ and $\mathrm{Er}$ ) were purchased from Chem Pur Feinchemikalien and Forschungsbedarf GmbH. Sodium fluoride $\left(\mathrm{NH}_{4} \mathrm{~F}, 99 \%\right)$ was purchased from Sigma Aldrich. Nitric acid solution $\left(\mathrm{HNO}_{3}, 65 \%\right)$, sodium chloride, polyvinylpyrrolidone (PVP 40) and ethanol (99.5\%) were purchased from Carl Roth. In the experiments double distilled water was used. In the synthesis all chemical reagents were used as received.

\subsection{Synthesis of $\mathrm{NaYF}_{4}: \mathrm{Yb}^{3+}: \mathrm{Er}^{3+}$ UCNPs}

The UCNPs were synthesized according to a previously reported procedure in which a well-known hydrothermal method with PVP 40 as a capping agent was applied. ${ }^{1,29,46}$ The rare earth nitrates $\left(\mathrm{RE}\left(\mathrm{NO}_{3}\right)_{3}\right)$ were prepared from the corresponding oxides in stoichiometric amounts of $\mathrm{Y}_{2} \mathrm{O}_{3}(3.9 \mathrm{mmol}), \mathrm{Yb}_{2} \mathrm{O}_{3}(1.0 \mathrm{mmol})$ and $\mathrm{Er}_{2} \mathrm{O}_{3}(0.1 \mathrm{mmol})$ dissolved in nitric acid $(200 \mathrm{~mL}, 10 \%)$ according to the literature method. ${ }^{47}$ Typically, the obtained $\mathrm{RE}\left(\mathrm{NO}_{3}\right)_{3}$, was dissolved in $200 \mathrm{~mL}$ ethylene glycol and was treated with a mixture of $\mathrm{NaCl}(20 \mathrm{mmol})$ and $8.9 \mathrm{~g}$ PVP 40 (solution A). $\mathrm{NH}_{4} \mathrm{~F}$ ( $80 \mathrm{mmol}$ ) was dissolved in $200 \mathrm{~mL}$ ethylene glycol and heated to $80{ }^{\circ} \mathrm{C}$ in a second reaction vessel until a clear solution was obtained (solution B). Subsequently, solution A was heated to $80{ }^{\circ} \mathrm{C}$ and solution B was released into the hot solution within a few seconds. The combined solutions were heated to $160{ }^{\circ} \mathrm{C}$. After $2 \mathrm{~h}$ the solution was cooled down to room temperature (RT) and the product was separated via centrifugation (4000 rpm for $20 \mathrm{~min}$ ). The particles were further purified alternately with water and absolute ethanol. Finally, the precipitate was dried at $85{ }^{\circ} \mathrm{C}$ for $5 \mathrm{~h}$ and a white powder was obtained. Taking into account the amount of volatile organic material present in the material (approximately 11\% mass loss according to thermo gravimetric studies) a yield of $75-90 \%$ was calculated. The composition of the UCNP is shown in Table 1. The chosen $\mathrm{Er}^{3+}$ concentration was small in order to eliminate possible cross relaxation between two excited $\mathrm{Er}^{3+}$ ions (see Scheme 1). To calculate the yields of the synthesis for different as-synthesized UCNPs a thermo-balance (L81 and STA PT-1600 Fa. Linseis) with simultaneously different thermal analysis (TG/DTA) was used.

Table 1 Nomenclature and basic parameters of the UCNPAS investigated. Particle size of UCNPAS nanoparticles was extracted from SEM images as well as calculated based on the Debye-Scherrer equation from XRD patterns

\begin{tabular}{ll}
\hline Parameter & $\mathrm{UCNP}_{\mathrm{AS}}$ \\
\hline $\mathrm{Yb}^{3+}: \mathrm{Er}^{3+}$ & $10: 1$ \\
Mean diameter $(\mathrm{SEM}) / \mathrm{nm}$ & $41 \pm 4$ \\
Mean diameter of nanocrystaline & $31 \pm 7$ \\
domain size $(\mathrm{XRD}) / \mathrm{nm}$ & \\
$T_{\text {an }} /{ }^{\circ} \mathrm{C}$ & $200-700($ for $5 \mathrm{~h})$ \\
Steps of annealing $/{ }^{\circ} \mathrm{C}$ & $\Delta T=20\left(\right.$ for $\left.200-300{ }^{\circ} \mathrm{C}\right)$ \\
& $\Delta T=100\left(\right.$ for $\left.300-700{ }^{\circ} \mathrm{C}\right)$
\end{tabular}

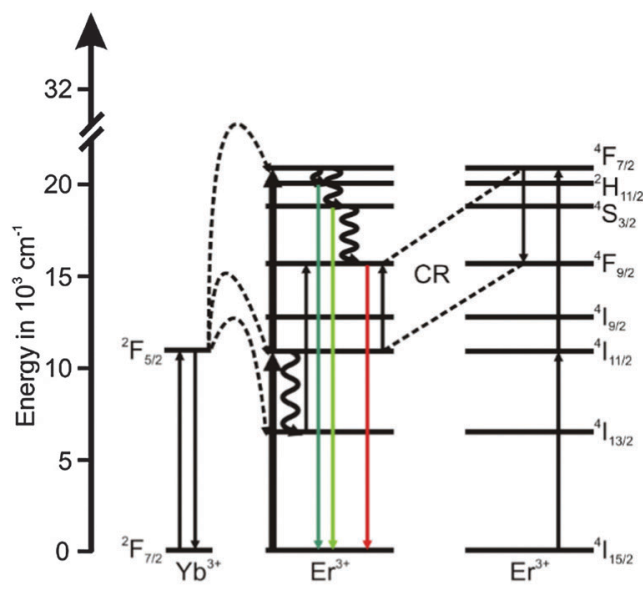

: energy transfer CR: crossrelaxation

$\mathcal{\xi}$ : non-radiative relaxation

Scheme 1 Schematic energy level diagram for the upconversion related processes of the $\mathrm{Yb}^{3+}$ (sensitizer) $\mathrm{Er}^{3+}$ (activator) system following an excitation at $\lambda_{\mathrm{ex}}=976 \mathrm{~nm}$. The full lines pointing upwards represent absorption, the dotted lines represent energy transfer, the waved lines represent non-radiative relaxation processes and the colored full lines pointing downwards represent emission. The cross-relaxation between two excited $\mathrm{Er}^{3+}$ ions is represented by "CR". 


\subsection{Annealing procedures}

The as-synthesized $\mathrm{UCNP}_{\mathrm{AS}}$ were subjected to annealing at different temperatures $T_{\mathrm{an}}$ in a range of $200{ }^{\circ} \mathrm{C}<T_{\mathrm{an}}<700{ }^{\circ} \mathrm{C}$ for $5 \mathrm{~h}$ using a muffle furnace (LM 212.11, VEB Elektro) to induce phase transitions in the $\mathrm{NaYF}_{4}$ host lattice (see Table 1). The UCNP materials are denoted as $\mathrm{UCNP}_{x}$ with $\mathrm{x}=\mathrm{AS}$ for as-synthesized and $\mathrm{x}=T_{\mathrm{an}}$ $\left(T_{\text {an }}=200-700^{\circ} \mathrm{C}\right)$.

\subsection{Structural characterization}

The size and morphology of the as-synthesized UCNP were obtained using a SEM S-4800 scanning electron microscope (Hitachi High-Technologies Canada, Inc., Toronto, Canada) operated with a cold field emission gun (FEG) as a cathode and an accelerating voltage of $2 \mathrm{kV}$. The samples were sputtered with platinum in order to reduce the tendency of electrostatic charging.

X-ray powder diffraction (XRD) patterns were collected using a D5005 instrument (Siemens AG, Munich, Germany) in a range of $3-70^{\circ} / 2 \theta$ with divergence aperture, scattering ray aperture and graphite monochromatized $\mathrm{Cu} \mathrm{K}_{\alpha}$ radiation $(\lambda=0.15406 \mathrm{~nm})$. The scanning step was $0.02 \%$ with a counting time of $4 \mathrm{~s}$ per step. From the XRD spectra the nanocrystalline domain sizes were calculated using the Debye-Scherrer equation (see eqn (1)):

$$
D=\frac{0.89 \lambda}{B \cos (\theta)}
$$

$D$ is the domain size to be determined, $\lambda$ is the wavelength of the $\mathrm{X}$-ray, $B$ is the FWHM of the diffraction peak of interest and $\theta$ is the angle of the corresponding diffraction peak.

Raman measurements were carried out using a confocal Raman microscope $300 \alpha$ (WITec Wissenschaftliche Instrumente und Technologie GmbH, Ulm, Germany) equipped with an upright optical microscope. For Raman excitation, laser light at $\lambda=532 \mathrm{~nm}$ was used, which was coupled into a single-mode optical fiber and focused through a $100 \times$ objective (Olympus MPlanFL N, NA $=0.9$ ) to a diffraction-limited spot of about $1.3 \mu \mathrm{m}^{2}$. The laser power was set between 0.4 and $1 \mathrm{~mW}$ and the integration time was $5 \mathrm{~s}$ for all samples under investigation. For the detection the UHTS 300 spectrograph (WITec, Wissenschaftliche Instrumente und Technologie GmbH, Ulm, Germany) was equipped with a grating (600 lines per $\mathrm{mm}$ ) and a cooled CCD camera (DU40LABR-DD-532, WITec, Wissenschaftliche Instrumente und Technologie GmbH, Ulm, Germany).

\subsection{Luminescence characterization}

2.5.1 Steady state and time resolved upconversion luminescence. Room temperature steady state and time resolved upconversion emission spectra of the solid samples were obtained using a wavelength tunable pulsed Nd:YAG/OPO laser system (pump laser: Quantaray, Spectra-Physics, Mountain View, CA, USA; OPO: GWU, GWU-Lasertechnik Vertriebsges. mbH, Erftstadt, Germany) operating at $20 \mathrm{~Hz}$ as an excitation light source and an intensified CCD-camera (iStar DH720-18H-13, Andor Technology, Belfast, Great Britain) coupled to a spectrograph (MS257 Modell $77700 \mathrm{~A}$, Oriel Instruments) equipped with a $3001 \mathrm{~mm}^{-1}$ grating as the detector. In order to record the time-resolved luminescence spectra (and subsequently extract the luminescence decay kinetics) the "box car" technique was applied. The initial gate delay $t_{\mathrm{I}}$ was set to $500 \mathrm{~ns}$, the gate width was adjusted between 10-100 $\mu \mathrm{s}$ and 350 spectra were recorded. For the measurements of the luminescence decay kinetics the time delay between the laser excitation pulse and the detection window was step-wise increased by the variable gate-step size $t_{\mathrm{v}}$ (see eqn (2)). This way more data points at shorter times after the laser excitation pulse were acquired in order to ensure a reliable analysis of components with fast luminescence decay kinetics.

$$
t(n)=t_{\mathrm{I}}+t_{\mathrm{v}}(n)=t_{\mathrm{I}}+\sum_{i=1}^{n}(i-1) \cdot t_{\mathrm{k}}
$$

$t(n)$ consists of $t_{\mathrm{I}}$, which is a constant of the chosen laser system and the constant step size $t_{\mathrm{k}}$, which is a luminescence decay dependent system specific parameter. $t_{\mathrm{v}}$ is a variable step size and $n$ (here $n=350$ ) the number of spectra acquired to record the luminescence decay kinetics, which was evaluated by eqn (3):

$$
I(t)=A+B_{1} \exp \left(-k_{1} t\right)+B_{2} \exp \left(-k_{2} t\right)
$$

From coefficients $B_{1}$ and $B_{2}$ the relative fractions $\alpha_{1}$ and $\alpha_{2}$ were calculated according to eqn (4):

$$
\alpha_{1}=\frac{B_{1} \tau_{1}}{\left(B_{1} \tau_{1}+B_{2} \tau_{2}\right)}
$$

The solid samples were measured at room temperature using a specifically designed sample holder for powder samples. The sample holder consists of a cylindrical brass base body with two different thread units. A quartz disc is attached with anodized aluminium cover on one thread. The sample was filled in the base body and sealed with an anodized aluminium stamp. The upconversion luminescence was excited at $\lambda_{\mathrm{ex}}=976 \mathrm{~nm}$.

2.5.2 Time-resolved area normalized emission spectra (TRANES). Measurements for TRANES analysis were carried out using a wavelength tunable pulsed Nd:YAG/OPO laser system (laser: Quanta Ray, Spectra-Physics, Mountain View, CA, USA; OPO: GWU-Lasertechnik Vertriebsges. mbH, Erftstadt, Germany) operating at $10 \mathrm{~Hz}$ as an excitation light source (at $26 \mathrm{~mJ} / 130 \mathrm{~mW}$ ) and recorded using an intensified CCD-camera (iStar DH 720 18V 73, Andor Technology, Belfast, Great Britain) coupled to a spectrograph (Shamrock SR-303i, Andor Technology, Belfast, Great Britain) equipped with a $6001 \mathrm{~mm}^{-1}$ grating. The "box car" technique was applied for this set of measurements as well (vide supra). The initial gate delay was set to $t_{\mathrm{I}}=500 \mathrm{~ns}$ and the gate width was adjusted between $\delta t=1-30 \mu$ s and 300 spectra were recorded. For the measurements the time delay between the laser excitation pulse and the detection window was step-wise increased by a constant gate-step size $t_{\mathrm{k}}$ (see eqn (5)).

$$
t(n)=t_{\mathrm{I}}+t_{n}(n)=t_{\mathrm{I}}+(n-1) \cdot t_{\mathrm{k}}
$$

For the TRANES based component analysis it was considered that a mixed spectra $\mathrm{m}(\lambda)$ consists of a combination of the alpha and beta phase spectra $\alpha(\lambda)$ and $\beta(\lambda)$ with the relative fractions $C$ and $D$, respectively (see eqn (6)). 


$$
\mathrm{m}(\lambda)=C \alpha(\lambda)+D \beta(\lambda)
$$

The fractions $(C$ and $D)$ of $\alpha$ - and $\beta$-phases were calculated based on the least squares method.

\section{Results and discussion}

\subsection{As-synthesized (cubic) $\mathrm{UCNP}_{\mathrm{AS}}$}

3.1.1 Basic characterization. The as-synthesized sample was first examined by XRD for its phase composition. For the $\mathrm{NaYF}_{4}$ host lattice two different thermodynamically stable phases, the cubic (isotropic) $\alpha$-phase and the hexagonal (anisotropic) $\beta$-phase, are known. ${ }^{20,48,49}$

The XRD diffractogram of $\mathrm{UCNP}_{\mathrm{AS}}$ with the corresponding Millerschen indices ${ }^{48}$ of the lattice planes is shown in Fig. 1 (left). A comparison of the XRD diffractogram with the database of the International center of diffraction data (ICCD, No. 77-2042) showed that $\mathrm{UCNP}_{\mathrm{AS}}$ is composed of the cubic $\alpha$-phase found for $\mathrm{NaYF}_{4}$. The very sharp reflexes of different lattice planes seen in the diffractograms indicate that even though the synthesis was carried out under mild conditions a defined crystal lattice was formed.

The particle size and morphology of $\mathrm{UCNP}_{\mathrm{AS}}$ were further studied using SEM. The SEM image of $\mathrm{UCNP}_{\mathrm{AS}}$ shows a cubic shape (Fig. 1, right). ${ }^{50-53}$ In order to determine an average particle size from SEM images approximately 500 particles were evaluated. The results of the statistical analysis of the SEM images are shown in Table 1. In addition, the particle size was calculated using the Debye-Scherrer equation. Here, the XRD data were fitted with Lorentz functions and the average particle diameter was obtained. In comparison to the SEM-based size the average diameter is determined approximately $25 \%$ smaller. Based on the Debye-Scherrer equation only the crystallite size of the particle is considered in the calculation, which accounts for the observed difference in size found by the two methods. Because of the mild synthesis conditions, the $\mathrm{UCNP}_{\mathrm{AS}}$ may not be fully crystallized and some amorphous domains may still be present in the particles.

3.1.2 Upconversion luminescence. In Fig. 2 (left) the luminescence spectrum of $\mathrm{UCNP}_{\mathrm{AS}}$ at $\lambda_{\mathrm{ex}}=976 \mathrm{~nm}$ is shown. The three typical emission bands can be observed in the green spectral region centered at $\lambda_{\mathrm{em}}=525 \mathrm{~nm}\left({ }^{2} \mathrm{H}_{11 / 2} \rightarrow{ }^{4} \mathrm{I}_{15 / 2}\right.$ transition, G1), $\lambda_{\mathrm{em}}=545 \mathrm{~nm}\left({ }^{4} \mathrm{~S}_{3 / 2} \rightarrow{ }^{4} \mathrm{I}_{15 / 2}\right.$ transition, G2)

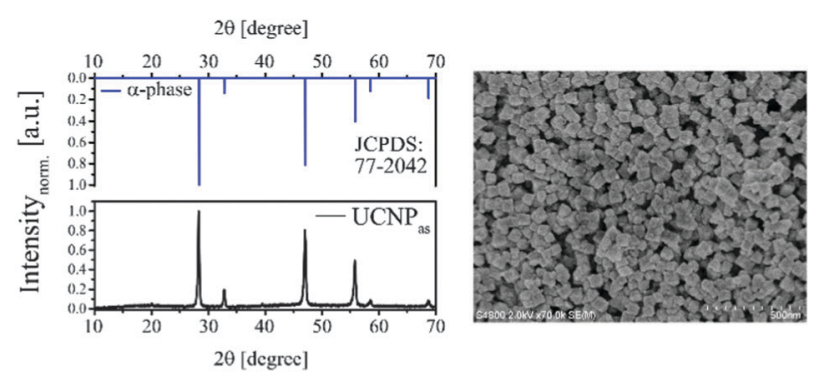

Fig. 1 (left) The XRD diffractogram of as-synthesized UCNP AS (and the corresponding reference data from JCPDS) indicates that the sample is composed of the pure cubic $\alpha$-phase. (right) SEM image (500 nm scale) of UCNP $_{\text {AS. }}$.
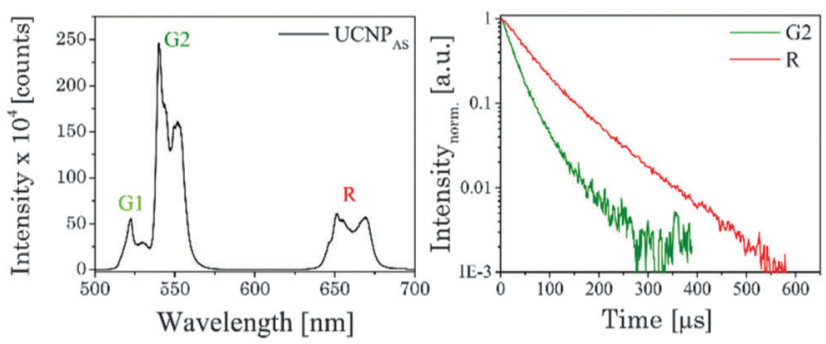

Fig. 2 (left) Upconversion luminescence spectrum of the as-synthesized

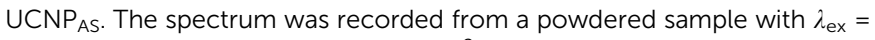
$976 \mathrm{~nm}$ (power density of $191 \mathrm{~mW} \mathrm{~cm}^{-2}$ ). (right) Normalized upconversion luminescence decay kinetics of the $\mathrm{Er}^{3+}$ emission bands G2 and R of UCNP ${ }_{\text {AS. }}$.

Table 2 Luminescence decay times $\tau$ with different time components and relative fractions of the as-synthesized UCNP ${ }_{\text {AS }}$ for the emission bands $\mathrm{G} 2$ and $\mathrm{R}$, respectively

\begin{tabular}{lrl}
\hline Decay time $[\mu \mathrm{s}]$ & $\mathrm{UCNP}_{\mathrm{AS}}$ & Relative fraction $[\%]$ \\
\hline$\tau_{\mathrm{G} 2,1}$ & $23 \pm 1$ & 71 \\
$\tau_{\mathrm{G} 2,2}$ & $65 \pm 5$ & 29 \\
$\tau_{\mathrm{R}, 1}$ & $51 \pm 1$ & 64 \\
$\tau_{\mathrm{R}, 2}$ & $118 \pm 6$ & 36
\end{tabular}

and in the red spectral region centered at $\lambda_{\mathrm{em}}=660 \mathrm{~nm}\left({ }^{4} \mathrm{~F}_{9 / 2} \rightarrow\right.$ ${ }^{4} I_{15 / 2}$ transition, R) (see also Scheme 1). ${ }^{9,54-57}$ The observed fine structures (Stark splitting) within the major emission peaks is induced by the crystal field of the ligands positioned around the $\mathrm{Er}^{3+}$ ions in the host lattice. ${ }^{55,56,58,59}$

Fig. 2 (right) shows the luminescence decay kinetics $\left(\lambda_{\mathrm{ex}}=976 \mathrm{~nm}\right)$ of $\mathrm{UCNP}_{\mathrm{AS}} \mathrm{G}$ and $\mathrm{R}$, respectively. For the emission bands G2 and R a distinctly different time dependence of the luminescence was observed (see Fig. 2, right), whereas no difference between G1 and G2 was observed (see ESI, $\dagger$ Fig. S1). In the data analysis a bi-exponential decay law was applied. ${ }^{55,60,61}$ As a trend, the calculated luminescence decay times $\left(\tau_{1}\right.$ and $\left.\tau_{2}\right)$ were longer for the red emission band (R) compared to the green emission bands (G1, G2) (Table 2).

\subsection{Annealed $\mathrm{UCNP}_{x}$}

The $\mathrm{NaYF}_{4}$ lattice shows a phase transition from cubic to hexagonal and as a consequence the upconversion properties of UCNPs are distinctly influenced due to structure-related parameters like lattice vibrations. To study the phase transfer from the cubic $(\alpha)$ to the hexagonal $(\beta)$ phase in more detail the $\mathrm{UCNP}_{\mathrm{AS}}$ were annealed at different temperatures $T_{\mathrm{an}}$.

At $T_{\text {an }}>400{ }^{\circ} \mathrm{C}$ the nanoparticles tend to build up microdomains (see ESI, $\dagger$ Fig. S2); therefore the samples are further denoted as $\operatorname{UCNP}_{x}$ materials. ${ }^{7}$

3.2.1 XRD. In Fig. 3 selected XRD diffraction patterns of $\mathrm{UCNP}_{x}$ after annealing in the temperature range of $200{ }^{\circ} \mathrm{C}<$ $T_{\text {an }}<700{ }^{\circ} \mathrm{C}$ for $5 \mathrm{~h}$ are shown. The overall intensity of the diffraction patterns was increased with increasing temperature $T_{\text {an }}$ (see ESI, $\dagger$ Fig. S3), whereas the FWHM of the different peaks stayed unaltered (see ESI, $\dagger$ Fig. S3). The increase in intensity is a good indication for an improved crystallinity of the $\mathrm{UCNP}_{x}$ upon annealing. The crystallite size was calculated using the 


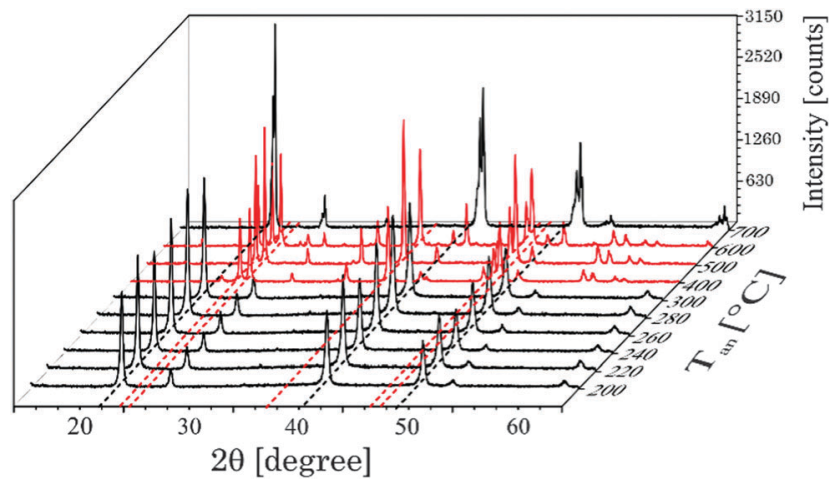

Fig. 3 Suited selection of $\mathrm{X}$-ray diffraction patterns of $\mathrm{UCNP}_{x}$ after annealing between $200{ }^{\circ} \mathrm{C}<T_{\text {an }}<700{ }^{\circ} \mathrm{C}$ for $5 \mathrm{~h}$. The black dotted lines correspond to the position of reflexes of the cubic phase whereas red dotted lines correspond to the position of reflexes of the hexagonal phase, respectively.

Debye-Scherrer equation (see ESI, $\dagger$ Table S1). It is obvious that there is a slight increase of the crystallite size for UCNPs annealed at $T_{\text {an }}<300{ }^{\circ} \mathrm{C}$, whereas for $300{ }^{\circ} \mathrm{C}<T_{\text {an }}<600{ }^{\circ} \mathrm{C}$ a significant increase of the crystallite size was found due to the change of the crystal phase of the host lattice and the formation of microdomains. In Fig. 3 for annealing temperatures below $300{ }^{\circ} \mathrm{C}$ only the cubic phase is observed in the XRD diffractogram, while for an annealing temperature of $T_{\mathrm{an}}=400{ }^{\circ} \mathrm{C}$ the hexagonal phase is clearly seen as the major crystal phase. The relative fraction of this phase gradually increased with increasing $T_{\text {an }}$ up to $500{ }^{\circ} \mathrm{C}$. Based on the XRD data (for $400{ }^{\circ} \mathrm{C}<T_{\text {an }}<500{ }^{\circ} \mathrm{C}$ ) only a minor amount of cubic phase seems to be present in the material (see Fig. 4). A further increase of $T_{\text {an }}>500{ }^{\circ} \mathrm{C}$ leads however to a decrease of the hexagonal phase and at $T_{\text {an }}=$ $700{ }^{\circ} \mathrm{C}$ again mainly the cubic phase was found in the XRD diffractograms. From Fig. 3 it can be seen that the $\mathrm{UCNP}_{700}$ material is slightly different in the observed XRD peak pattern indicating that the phase back transfer may not be fully completed. This has been observed before for bulk materials by Hebert et al. ${ }^{62-64}$

3.2.2 Raman spectroscopy. In the Raman spectra of $\mathrm{UCNP}_{\mathrm{AS}}$ (cubic phase) two dominant broad bands around $\nu=275 \mathrm{~cm}^{-1}$

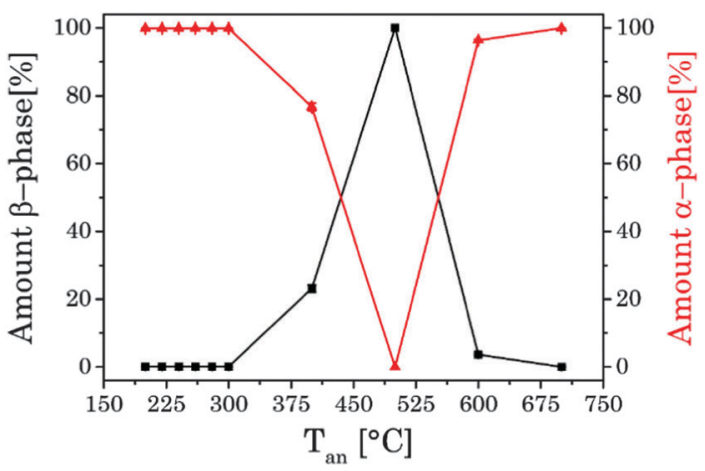

Fig. 4 Amount of $\alpha$ - and $\beta$-phase in correlation with temperature of the thermal treatment, calculated on the intensity of different XRD reflexes of $\alpha$ - and $\beta$-phases. and $745 \mathrm{~cm}^{-1}$ were observed, which were also found for $\mathrm{UCNP}_{x}$ annealed up to $T_{\text {an }}<300{ }^{\circ} \mathrm{C}$. Moreover, the comparison of the samples annealed at $T_{\text {an }}<300{ }^{\circ} \mathrm{C}$ and the sample annealed at $T_{\text {an }}=700{ }^{\circ} \mathrm{C}$ showed only small differences with respect to the peak position and spectral distribution (see Fig. 5, left top). These results are complementary to the corresponding XRD data (vide supra) pointing to a cubic phase for the respective materials. The Raman spectra of the hexagonal phase materials display five main peaks at $\nu=251 \mathrm{~cm}^{-1}, 303 \mathrm{~cm}^{-1}, 359 \mathrm{~cm}^{-1}, 492 \mathrm{~cm}^{-1}$ and $625 \mathrm{~cm}^{-1}$, whereas the high phonon vibrational bands $\nu>700 \mathrm{~cm}^{-1}$, which have been found for the cubic phase materials, are only weakly present (see Fig. 5). ${ }^{65,66}$ The observed alterations in the Raman spectra are well correlated with the phase transition of the host lattice seen in the XRD diffractograms. Moreover, also the small differences between the sample annealed at $T_{\text {an }}=700{ }^{\circ} \mathrm{C}$ and samples for $T_{\text {an }}<300{ }^{\circ} \mathrm{C}$ are confirmed by the Raman spectra (see Fig. 5).

3.2.3 Upconversion luminescence. The upconversion luminescence of the UCNP materials is investigated in detail using (quasi) steady state and time-resolved luminescence techniques. In the (quasi) steady state luminescence measurements a detection window of $500 \mu \mathrm{s}$ was used collecting more than $95 \%$ of the overall luminescence intensity. In the upconversion luminescence spectra the intensity as well as the spectral intensity distribution were altered due to annealing (see Fig. 6). For $T_{\text {an }}<300{ }^{\circ} \mathrm{C}$ a small increase in the upconversion luminescence intensity was found, but no alteration in the spectral intensity distribution was observed (see ESI, $\dagger$ Fig. S4). For annealing temperatures in the range of $300{ }^{\circ} \mathrm{C}<T_{\text {an }}<600{ }^{\circ} \mathrm{C}$ a distinct increase in the overall upconversion luminescence intensity was found with a maximum at $T_{\text {an }}=500{ }^{\circ} \mathrm{C} .{ }^{18,68-70}$ In addition, for this set of samples the spectral intensity distribution was changed as well. Within different emission bands (G1, G2, and R) Stark level-related substructures became apparent, but also the relative contribution of the G- and R-bands was altered (see Fig. 6).

While the ratio of G1/G2 was found to be nearly independent of the annealing temperature the ratio G2/R showed a distinct change for $T_{\text {an }}>300{ }^{\circ} \mathrm{C}$ (see Fig. 6). The sample obtained at

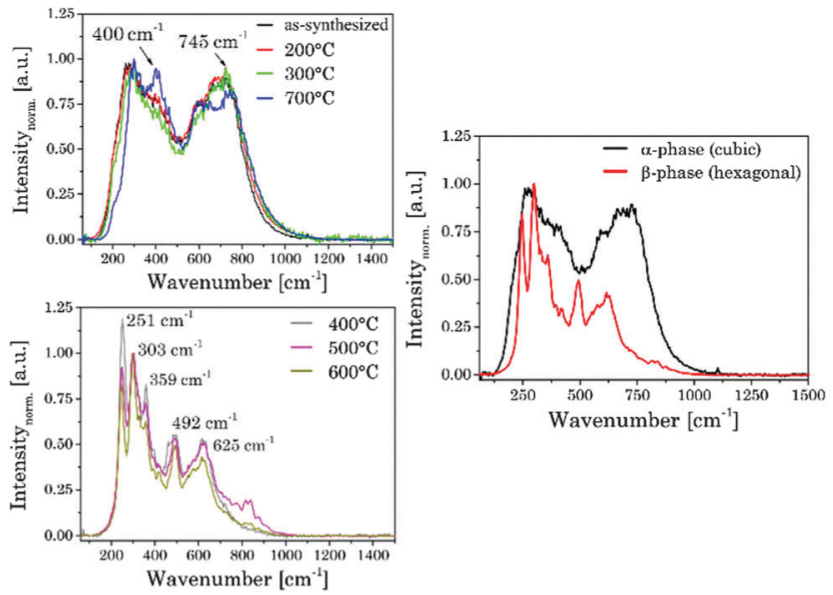

Fig. 5 (left) Normalized Raman spectra of the as-synthesized UCNP As and annealed $U C N P_{x}$. (right) Representative Raman spectra of $\alpha$ - and $\beta$-phases. 

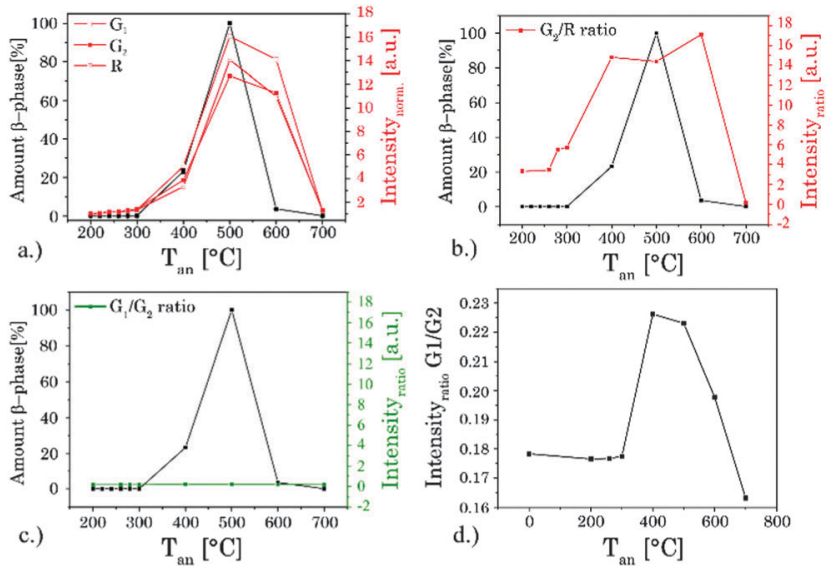

Fig. 6 (a) Alteration in the (quasi) steady state intensity of different luminescence bands with annealing temperature $T_{\text {an }}$. The ratio G2/R (b) and G1/G2 (c) based on the integrated steady state luminescence intensity of these emission bands and the amount of hexagonal $\beta$-phase, both as a function of temperature $T_{\text {ann }}$. The amount of $\beta$-phase was calculated based on XRD measurements. (d) Enlargement of the G1/G2 ratio over $T_{\text {an }}$.

$T_{\text {an }}=700{ }^{\circ} \mathrm{C}$ showed a reversed effect, here the overall intensity as well as the spectral intensity distribution were changed back according to materials obtained for $T_{\text {an }}<300{ }^{\circ} \mathrm{C}$. In Fig. 6 the overall intensity, the ratio G2/R (as well as the G1/G2 ratio), and the amount of $\beta$-phase in different samples are compared. ${ }^{71}$ The spectral changes are well correlated with the phase transition from the cubic $(\alpha)$ phase to the hexagonal $(\beta)$ phase corroborating the results of the XRD and Raman measurements. ${ }^{34,41,44}$ In addition, for high $T_{\text {an }}$ a reduction in lattice defects due to the annealing process and a subsequent decrease of radiationless deactivation improving the energy migration between $\mathrm{Yb}^{3+}$ ions within the crystal may also have a positive effect on the overall upconversion luminescence intensity.

3.2.4 Laser power dependent luminescence measurements. The UC luminescence intensity $\left(I_{\mathrm{UC}}\right)$ is proportional to the " $n$ th" of excitation power $\left(I_{\mathrm{IR}}\right)$ (see eqn (7)).

$$
I_{\mathrm{UC}} \sim I_{\mathrm{IR}}^{n}
$$

$n$ is the number of absorbed NIR photons per visible photon emitted and can be obtained from the slope of $\log \left(I_{\mathrm{UC}}\right)$ versus $\log \left(I_{\mathrm{IR}}\right)$ analysis (see Fig. 7). ${ }^{61,72-76}$

For G1 and G2 luminescence two NIR photons need to be transferred ( $n=2$, see Fig. 7) from two $\mathrm{Yb}^{3+}$ ions (sensitizer) to one $\mathrm{Er}^{3+}$ ion (activator). ${ }^{61,72,73}$

First, the ${ }^{4} \mathrm{I}_{11 / 2}$ energy level and then the ${ }^{4} \mathrm{~F}_{7 / 2}$ energy level of $\mathrm{Er}^{3+}$ are populated. Followed by a non-radiative deactivation from the ${ }^{4} \mathrm{~F}_{7 / 2}$ to the ${ }^{2} \mathrm{H}_{11 / 2}$ energy level (G1) or further to the ${ }^{4} \mathrm{~S}_{3 / 2}$ energy level (G2). Alternatively the ${ }^{4} \mathrm{~S}_{3 / 2}$ energy level can also be deactivated non-radiatively through multiphonon interaction with the host lattice to the ${ }^{4} \mathrm{~F}_{9 / 2}$ energy level yielding the emission band $\mathrm{R}$ (also via two energy transfer steps, $n=2$ ). In addition, the ${ }^{4} \mathrm{~F}_{9 / 2}$ energy level can be populated via the two different three photon energy transfer process $(n=3){ }^{20,55,56,67,77}$

The ${ }^{4} \mathrm{~S}_{3 / 2}$ energy level of one $\mathrm{Er}^{3+}$ ion is populated by two energy transfer steps from excited $\mathrm{Yb}^{3+}$ ions whereas a second
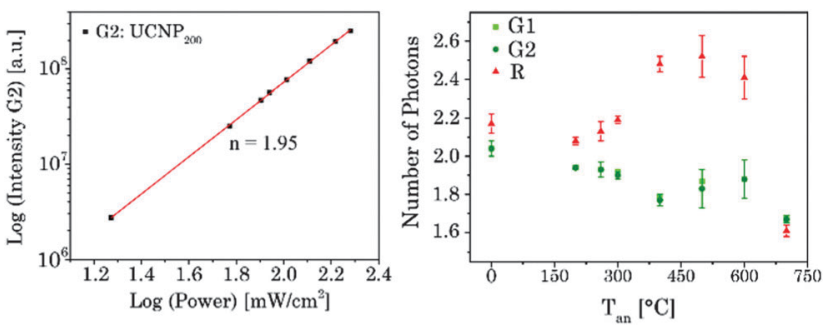

Fig. 7 (left) Dependence of upconversion luminescence intensity on laser power for $G 2$ related emission of $U_{C N P_{200}}$. (right) $n$-Values determined for the emission bands G1, G2, and R for $U_{C N P}$ annealed at different $T_{\text {an }}$.

$\mathrm{Er}^{3+}$ ion is in the ${ }^{4} \mathrm{I}_{11 / 2}$ energy level via one energy transfer step from $\mathrm{Yb}^{3+}$. Following a cross relaxation between the two excited $\mathrm{Er}^{3+}$ ions both $\mathrm{Er}^{3+}$ ions reached the ${ }^{4} \mathrm{~F}_{9 / 2}$ energy level from which the red emission (R) can occur (three photon process $\mathrm{A}$ ). The three photon process $\mathrm{A}$ is only possible at high $\mathrm{Er}^{3+}$ concentration and can be neglected in our materials due to the low $\mathrm{Er}^{3+}$ concentration. ${ }^{57,67,78-80}$ In a second three photon process $\mathrm{B}$ the ${ }^{4} \mathrm{~S}_{3 / 2}$ energy level of the $\mathrm{Er}^{3+}$ ion is populated by two energy transfer steps from excited $\mathrm{Yb}^{3+}$ ions. Then, the ${ }^{4} \mathrm{I}_{13 / 2}$ level of $\mathrm{Er}^{3+}$ can be populated via an energy back transfer (BET) from the ${ }^{4} \mathrm{~S}_{3 / 2}$ level of $\mathrm{Er}^{3+}$ to neighbouring $\mathrm{Yb}^{3+}$ ions. ${ }^{81}$ A subsequent energy transfer from excited $\mathrm{Yb}^{3+}$ ions to the ${ }^{4} \mathrm{I}_{13 / 2}$ level of $\mathrm{Er}^{3+}$ leads to the population of the ${ }^{4} \mathrm{~F}_{9 / 2}$ energy level and the red emission band $\mathrm{R}^{82}$ The $n$-value for $\mathrm{G} 1$ and $\mathrm{G} 2$ is slightly, but steadily decreased with increasing annealing temperature from $n-2\left(\mathrm{UCNP}_{\mathrm{AS}}\right)$ to $n-1.7$ (for $T_{\mathrm{an}}=700{ }^{\circ} \mathrm{C}$ ) (see Fig. 7 , right). In contrast the $n$-value for the $\mathrm{R}$ band increased from $n-2.1\left(\mathrm{UCNP}_{\mathrm{AS}}\right)$ to $n-2.5\left(T_{\mathrm{an}}=600{ }^{\circ} \mathrm{C}\right)$. A distinct difference in the $n$-values is found for the cubic phase $\left(\mathrm{UCNP}_{\mathrm{AS}}\right)$ and the hexagonal phase $\left(\mathrm{UCNP}_{400}\right)$, but already at $T_{\text {an }}<400{ }^{\circ} \mathrm{C}$ a slight but steady change in the $n$-values was observed (see Fig. 7 (right)). Opposing effects originating from the differences in phonon coupling in the cubic and hexagonal lattices as well as from the interplay between radiationless deactivation and saturation effects at higher laser power may be the reason for the observed trends in $n$ for the $\mathrm{G}$ and $\mathrm{R}$ band(s), respectively. While for the green emission bands G1 and G2 theoretically $n=2$ is expected and the observed decrease of $n$ with increasing $T_{\text {an }}$ points toward a saturation effect, for the $\mathrm{R}$ band the change in the matrix-related phonon coupling is the major factor responsible for the overall increase of $n \cdot{ }^{61,83}$ To further elucidate different factors the power dependence of the spectral intensity distribution was analyzed in more detail. In Fig. 8 the ratio of the green luminescence bands G1/G2 (left) as well as the ratio of the overall green and red luminescence $\mathrm{G}_{\text {full }} / \mathrm{R}$ (right) are shown for different laser power $\left(\lambda_{\mathrm{ex}}=976 \mathrm{~nm}\right)$. For the $\mathrm{G} 1 / \mathrm{G} 2$ ratio almost no influence of the laser power is found for the $\mathrm{UCNP}_{x}$ annealed at $T_{\text {an }}<300{ }^{\circ} \mathrm{C}$. For $T_{\text {an }}>300{ }^{\circ} \mathrm{C}$ a slight jump in the G1/G2 ratio was found but no significant influence of the laser power. The observed "jump" falls well within the range of $T_{\text {an }}$ for which the hexagonal phase is dominant. ${ }^{72,74}$ At $T_{\text {an }}=700{ }^{\circ} \mathrm{C}$ a decrease and a slight power dependence were observed for the G1/G2 ratio. It is known that $\mathrm{G} 1$ is mainly populated via thermal excitation from the ${ }^{4} \mathrm{~S}_{3 / 2}$ level (G2). The energy gap between the 

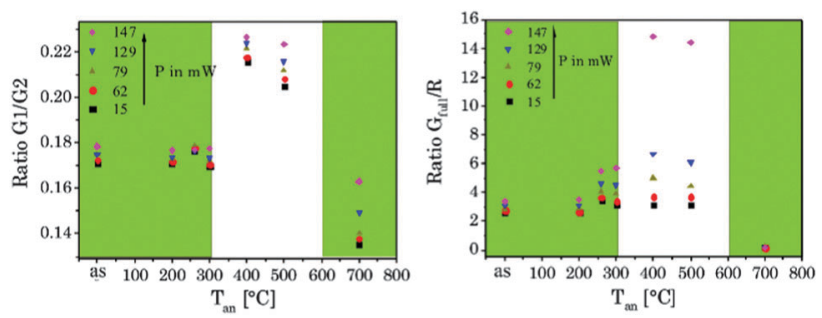

Fig. 8 Peak ratio G1/G2 (left) and $G_{\text {full }} / R$ (right) versus annealing temperature at different laser power $P$. The green inlet represents the alpha phase and the white inlet the beta phase of the host lattice $\left(\lambda_{\mathrm{ex}}=976 \mathrm{~nm}\right)$.

${ }^{4} \mathrm{~S}_{3 / 2}$ - and ${ }^{2} \mathrm{H}_{11 / 2}$ level is decreased due to thermal treatment (associated therewith phase transfer from the $\alpha$ - to $\beta$-phase) and leads to a more efficient thermal population of the ${ }^{2} \mathrm{H}_{11 / 2}$ level, subsequently increasing the G1/G2 ratio (see Fig. 8, left). In contrast, for the $\mathrm{G}_{\text {full }} / \mathrm{R}$ ratio a distinct laser power dependence was found. Especially in the range of $300{ }^{\circ} \mathrm{C}<T_{\text {an }} \leq 600{ }^{\circ} \mathrm{C}$ representative for the hexagonal phase a large increase by a factor of about 7 was measured (see Fig. 8, right). As for the G1/G2 ratio at $T_{\text {an }}=700{ }^{\circ} \mathrm{C}$ the $\mathrm{G}_{\text {full }} / \mathrm{R}$ ratio dropped back (even below) to the value found for $T_{\text {an }}<300{ }^{\circ} \mathrm{C}$ and the laser power influence disappeared. The energy mismatch of the ${ }^{2} \mathrm{~F}_{5 / 2}$ level of $\mathrm{Yb}^{3+}$ and the ${ }^{4} \mathrm{I}_{11 / 2}$ level of $\mathrm{Er}^{3+}$ is smaller in the hexagonal phase than in the cubic phase and a better phonon matched energy transfer process between $\mathrm{Yb}^{3+}$ - and $\mathrm{Er}^{3+}$-ions is possible which accounts for the observed lattice phase influence (especially for the $\mathrm{G} 1 / \mathrm{G} 2$ ratio). The possibility of saturation effects (e.g., BET, cross relaxation) might also be increased due to the improved phonon matching. In the case of the $\mathrm{G}_{\text {full }} / \mathrm{R}$ ratio the alteration of the $\mathrm{R}$ is the dominant factor. In the case of a high concentration of excited $\mathrm{Yb}^{3+}$ ions (sensitizers) the activation into the ${ }^{4} \mathrm{~F}_{7 / 2}$ state becomes faster and can successfully compete with the radiationless deactivation from the ${ }^{4} \mathrm{I}_{11 / 2}$ into the ${ }^{4} \mathrm{I}_{13 / 2}$ state, which is a necessary prior step to the activation into the ${ }^{4} \mathrm{~F}_{9 / 2}$ state. From the ${ }^{4} \mathrm{~F}_{9 / 2}$ state $\mathrm{R}$ emission occurs subsequently (see Scheme 2).

3.2.5 Time-resolved luminescence. The luminescence decay kinetics of the $\mathrm{UCNP}_{x}$ materials showed a complex time dependence. In Fig. 9 the luminescence decay kinetics $\left(\lambda_{\mathrm{ex}}=976 \mathrm{~nm}\right)$ of UCNP 300 is shown for the two emission bands G2 and R. It can be seen that the kinetics of the two bands shows a distinctly different time dependence.

For $\mathrm{R}$ an initial rise in the luminescence intensity is observed (for $t<500 \mu$ s, see Fig. 9). The complexity of the observed decay kinetics could be a result of the contributions from $\mathrm{Er}^{3+}$ ions located in different chemical environments (e.g., surface vs. volume effects, amorphous domains, which are reduced due to annealing). The experimental data of G1, G2 and $\mathrm{R}$ were analyzed by a bi-exponential decay kinetics.

Luminescence decay times $\tau_{1}$ and $\tau_{2}$ were calculated for different bands $\mathrm{G} 1, \mathrm{G} 2$ and $\mathrm{R}$ of the $\mathrm{UCNP}_{x}$ materials. An increase in both luminescence decay times with increasing $T_{\text {an }}$ was observed. Moreover, at $T_{\text {an }}>300{ }^{\circ} \mathrm{C}$ for both luminescence decay times an accelerated increase with increasing $T_{\text {an }}$ was calculated (see Fig. 10). This trend in the decay time is accompanied by the crystal phase transfer from cubic to hexagonal (vide supra).

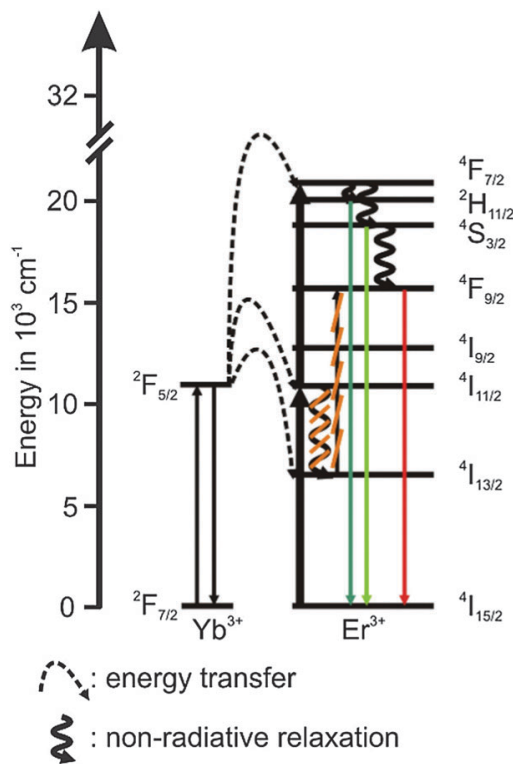

Scheme 2 Energy scheme of the upconversion processes in the hexagonal phase with suppressed population route of the ${ }^{4} \mathrm{~F}_{9 / 2}$ level (underlined by the orange lines).

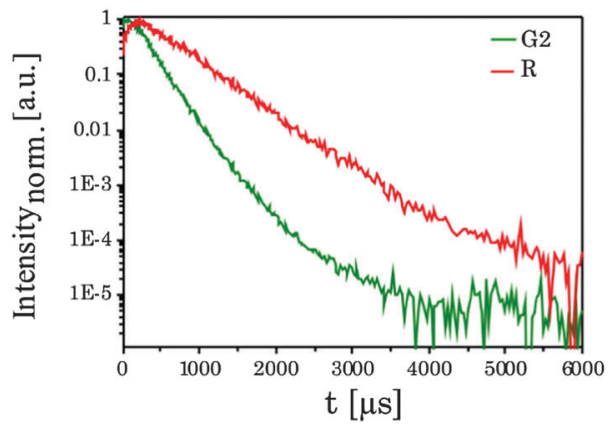

Fig. 9 Normalized upconversion luminescence decays of the G2 and $\mathrm{R}$ bands of $\mathrm{Er}^{3+}$ in $\mathrm{UCNP}_{300}\left(\lambda_{\mathrm{ex}}=976 \mathrm{~nm}\right)$.

The drop observed for $\tau_{1}$ and $\tau_{2}$ at $T_{\mathrm{an}}=700{ }^{\circ} \mathrm{C}$ (here, the material switched back to a cubic phase) supports the correlation of the luminescence decay kinetics and the lattice phase. The results of the luminescence kinetics measurements are in very good agreement with the other spectroscopic data presented for the $\mathrm{G} 1 / \mathrm{G} 2$ and $\mathrm{G}_{\text {full }} / \mathrm{R}$ ratios.

3.2.6 Time-resolved area normalized emission spectra (TRANES). In order to pinpoint the influence of the lattice on the luminescence upconversion the time-resolved emission spectra were evaluated by TRANES analysis. TRANES can be used to reveal small time-dependent variations in the spectral intensity distribution of a luminescence spectrum. They were calculated from the time-resolved emission spectra recorded for the determination of the luminescence decay kinetics by normalizing the area of the emission spectrum recorded at different delay times after the laser pulse (e.g., area of spectrum is normalized to one). In Fig. 11 (top) the TRANES of UCNP 200 are shown. No change in the spectral intensity distribution neither for the G1 and G2 luminescence nor for the R 

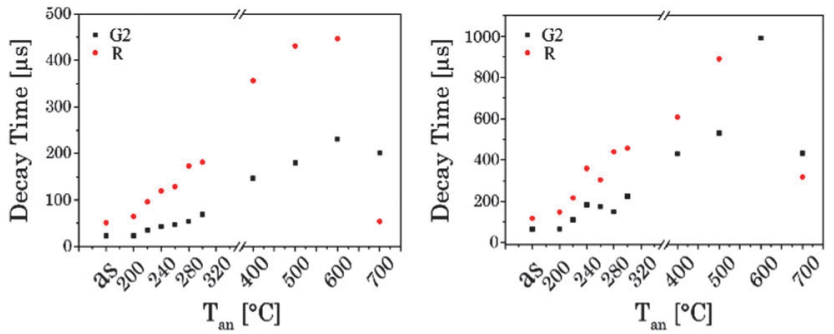

Fig. 10 Luminescence decay times of UCNPs annealed at different $T_{\text {an }}$ for the emission bands G2 and R, (left) the short decay component, (right) and the long decay component $\left(\lambda_{\mathrm{ex}}=976 \mathrm{~nm}\right)$.

luminescence is detected. For $\mathrm{UCNP}_{300}$ a significant change in the intensity distribution of the luminescence is found for G1 and G2 as well as for R (see Fig. 12). In the TRANES isoemissive points are found. For example, for $\mathrm{G} 1$ isoemissive points can be seen at $\lambda_{\mathrm{em}}=516.8 \mathrm{~nm}, 521.8 \mathrm{~nm}$ and $523.2 \mathrm{~nm}$ and the luminescence peak at $\lambda_{\mathrm{em}}=529 \mathrm{~nm}$ becomes more pronounced (see Fig. S4, ESI $\dagger$ ). Also in the case of G2 the intensity distribution is altered with increasing delay relative to the excitation pulse. For the $\mathrm{R}$ luminescence two isoemissive points are identified at $\lambda_{\mathrm{em}}=651 \mathrm{~nm}$ and $665.8 \mathrm{~nm}$. Furthermore, the shoulder at $\lambda_{\mathrm{em}}=668 \mathrm{~nm}$ is decreased whereas a completely new peak appears at $\lambda_{\mathrm{em}}=661 \mathrm{~nm}$. In Fig. 11 the upconversion emission spectra of $\mathrm{UCNP}_{400}$ and $\mathrm{UCNP}_{600}$ are shown as well. The variations in the spectral intensity distribution of G1 and G2 as of $\mathrm{R}$ are small for both materials (the luminescence intensity
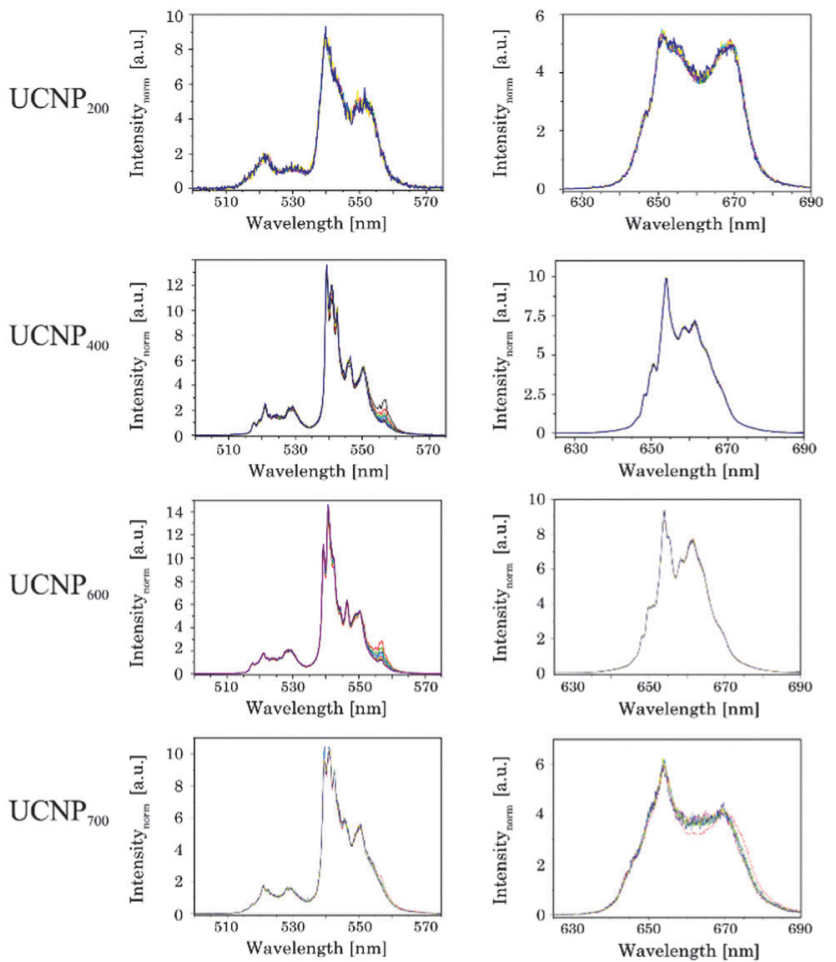

Fig. 11 TRANES of annealed $\operatorname{UCNP}_{x}\left(200^{\circ} \mathrm{C}<x<700^{\circ} \mathrm{C}\right)$ for (left) G1 and G2 luminescence as well as (right) of $R$ luminescence are shown $\left(\lambda_{\text {ex }}=\right.$ $976 \mathrm{~nm}$ ). The delay after the laser pulse was varied between $0 \mu \mathrm{s}$ and $2000 \mu \mathrm{s}$.
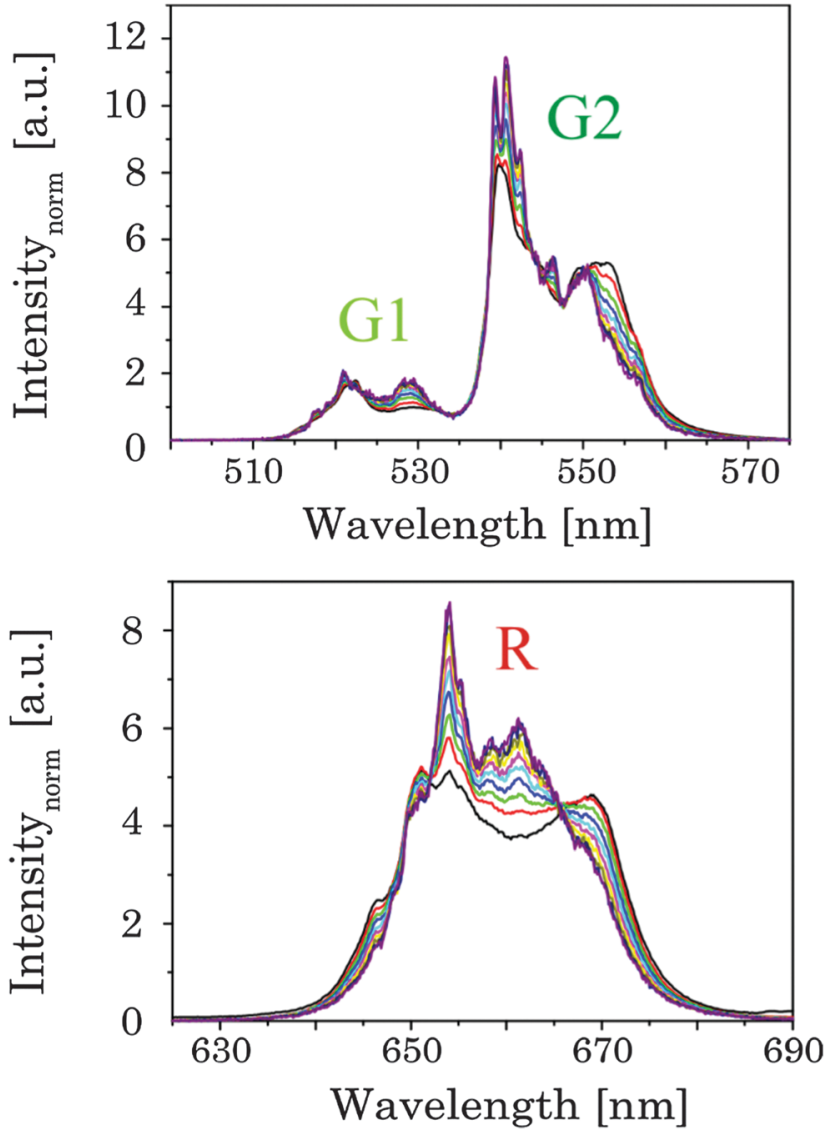

Fig. 12 TRANES of annealed UCNP 300 for (up) G1 and G2 luminescence as well as (below) of $R$ luminescence are shown $\left(\lambda_{\text {ex }}=976 \mathrm{~nm}\right)$. The delay after the laser pulse was varied between $0 \mu$ s and $2000 \mu$ s (displayed by the colors in $120 \mu$ s steps).

distribution is only slightly changed for the emission band G2). For the TRANES analysis of $\mathrm{UCNP}_{700}$ it can be seen that the spectral intensity distribution remains unchanged with increasing delay time. Moreover, a comparison with the spectra of $\mathrm{UCNP}_{200^{-}}$ $\mathrm{UCNP}_{600}$ materials shows that for the $\mathrm{UCNP}_{700}$ material a close resemblance to the $\mathrm{UCNP}_{200}$ material is found (especially for the R luminescence). The results of the TRANES analysis nicely complement the data of the other experimental techniques reflecting the phase transition from cubic to hexagonal (and back to cubic) upon annealing in the temperature range $200{ }^{\circ} \mathrm{C}<T_{\text {an }}<700{ }^{\circ} \mathrm{C}$. However, while the other analytical techniques and data evaluation approaches gave only a rough picture of the phase transfer and its initial temperature $T_{\mathrm{an}}$, in the TRANES analysis of the G1, G2 and R emission bands already small fractions of the hexagonal phase could be detected. The fact that the shape of the emission bands is changed with increasing delay time after the laser pulse in favor of the hexagonal phase related luminescence is a consequence of the significant differences in the decay times of $\mathrm{Er}^{3+}$ luminescence in the two lattice phases involved due to difference in the symmetry of the chemical environment (vide supra). Consequently the relative luminescence intensity contribution of $\mathrm{Er}^{3+}$ ions located in the cubic and hexagonal phases changes with time after the laser pulse and different lattice environments, if present, can be identified in 

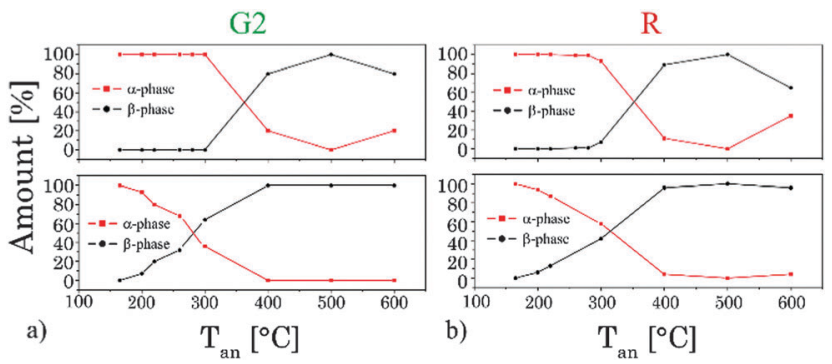

Fig. 13 Variation of the amount of different crystal phases ( $\alpha$ - and $\beta$ phases) calculated out of the TRANES analysis at delay times after the laser pulse (top: $0 \mu$ s and bottom: $500 \mu \mathrm{s}$ ) for emission bands G2 (a) and R (b).

the sample from the alteration in the spectral intensity distribution. The TRANES analysis is very sensitive and allows the analysis of even a small difference in the material composition. The small differences in the intensity distribution of G1 and G2 of the $\mathrm{UCNP}_{700}$ material compared to $\mathrm{UCNP}_{200}$ indicate a small fraction of the hexagonal phase to be still present in this material. For a complete back transfer to the cubic phase higher temperatures or/and longer annealing times seem to be necessary. Based on the diffractogram and the corresponding Debye-Scherrer calculations an increase in the crystallite size as well as an asymmetric growth of the UCNP was found, which could also have an impact on the intensity distribution of $\mathrm{G} 1$ and $\mathrm{G} 2$ of the $\mathrm{UCNP}_{700}$ material. Based on the approximation that in the $\mathrm{UCNP}_{\mathrm{AS}}$ and the $\mathrm{UCNP}_{500}$ only cubic and hexagonal phases, respectively, are present, a spectral decomposition of the emission spectra recorded at a delay time of $0 \mu \mathrm{s}$ and $500 \mu \mathrm{s}$ was performed in order to calculate the relative amount of cubic and hexagonal phases for different $\operatorname{UCNP}_{x}$ materials (see Fig. 13). It can be seen that in the temperature range of $200{ }^{\circ} \mathrm{C}<T_{\text {an }}<400{ }^{\circ} \mathrm{C}$ a gradual transformation of the cubic into the hexagonal phase is already present.

\section{Conclusion}

$\mathrm{NaYF}_{4}$ nanoparticles co-doped with $\mathrm{Er}^{3+}$ and $\mathrm{Yb}^{3+}$ were synthesized under mild conditions using PVP 40 as a capping agent and as a stabilizer, respectively. The $\mathrm{UCNP}_{\mathrm{AS}}$ were uniform in size and shape with a cubic crystal lattice. After annealing between $200{ }^{\circ} \mathrm{C}<T_{\text {an }}<700{ }^{\circ} \mathrm{C}$ for $5 \mathrm{~h}$ changes in the crystal lattice phase and subsequently in the upconversion luminescence properties of the UCNP materials were induced. The lattice phase and the structure of the UCNP materials obtained at different $T_{\text {an }}$ were analyzed using XRD, Raman spectroscopy as well as SEM. The upconversion luminescence properties of the annealed UCNP materials were studied by steady state and time resolved luminescence. Upconversion luminescence proved to be a sensitive tool to monitor the phase transition of the host lattice. While based on XRD and Raman spectroscopy no clear indication for a change in the lattice phase was found for $T_{\mathrm{an}}<300{ }^{\circ} \mathrm{C}$, the upconversion luminescence proved to be more sensitively capable of resolving even small contributions of cubic and hexagonal phases, respectively, in the materials. Based on the upconversion fluorescence studies of the $\mathrm{UCNP}_{x}$ materials the complex interplay of the host lattice crystal phases and the population routes of the $\mathrm{Er}^{3+}$ energy levels involved in the upconversion processes was evaluated. The laser power dependence of the green (G1, G2) and red (R) luminescence was found to be dependent on the annealing temperature. In addition, green and red luminescence was found to respond differently in the host lattice phase. A major population route of the $\mathrm{R}$ luminescence is attenuated at higher laser power, which is more efficient for the hexagonal lattice phase; the relative contributions expressed as the ratio between $\mathrm{G}_{\text {full }}$ and $\mathrm{R}$ are altered (see Scheme 2). Although already regular upconversion data, like spectral intensity distribution from steady state luminescence measurements or luminescence decay kinetics, show a clear lattice phase dependent behavior, TRANES analysis proved to be superior. The basis for the full exploitation of the power of TRANES is the different luminescence decay kinetics of the upconversion in cubic and hexagonal lattice phases. Because the analysis of the luminescence kinetics with respect to physical meaningful luminescence decay times is difficult due to the complex time dependence and the related challenges in the data analysis, TRANES employ a model-free combination of time and spectral information. Based on TRANES even minor amounts of cubic or hexagonal phase could be identified in different UCNP materials. TRANES could also be a great tool for monitoring the phase composition of UCNP in situ during synthesis. ${ }^{84,85}$

\section{Acknowledgements}

We are thankful to Dr C. Günter and Dr C. Prietzel (work group of Prof. J. Kötz) for XRD and SEM measurements of the samples, respectively.

\section{References}

1 Z. Li and Y. Zhang, Angew. Chem., Int. Ed., 2006, 45, 7732-7735.

2 J. Yin, Y. Hu and J. Yoon, Chem. Soc. Rev., 2015, 44, 4619-4644.

3 N. Kaur, W. Hyland and J. F. Callan, Chem. Soc. Rev., 2015, 44, 4415-4432.

4 T. D. Ashton, K. a. Jolliffe and F. M. Pfeffer, Chem. Soc. Rev., 2015, 44, 4547-4595.

5 Y. Tang, D. Lee, J. Wang, G. Li, J. Yu, W. Lin and J. Yoon, Chem. Soc. Rev., 2015, 44, 5003-5015.

6 L. Niu, Y. Chen, H. Zheng, L. Wu, C. Tung and Y. Chen, Chem. Soc. Rev., 2015, 44, 6143-6160.

7 G. Yi, H. Lu, S. Zhao, Y. Ge and W. Yang, Nano Lett., 2004, 4, 2191-2196.

8 J. Shan, W. Kong, R. Wei, N. Yao and Y. Ju, J. Appl. Phys., 2010, 107, 054901.

9 K. Wu, J. Cui, X. Kong and Y. Wang, J. Appl. Phys., 2011, 110, 053510.

10 J. Shen, Y. Zhu, X. Yang and C. Li, Chem. Commun., 2012, 48, 3686. 
11 S. Zhu, J. Zhang, C. Qiao, S. Tang, Y. Li, W. Yuan, B. Li, L. Tian, F. Liu, R. Hu, H. Gao, H. Wei, H. Zhang, H. Sun and B. Yang, Chem. Commun., 2011, 47, 6858-6860.

12 M. Montalti, A. Cantelli and G. Battistelli, Chem. Soc. Rev., 2015, 44, 4853-4921.

13 S. Silvi and A. Credi, Chem. Soc. Rev., 2015, 44, 4275-4289.

14 K. D. Wegner, N. Hildebrandt and N. Hildebrandt, Chem. Soc. Rev., 2015, 44, 4792-4834.

15 O. S. Wolfbeis, Chem. Soc. Rev., 2015, 44, 4743-4768.

16 H. Peng and D. T. Chiu, Chem. Soc. Rev., 2015, 44, 4699-4722.

17 J. Thomas, Chem. Soc. Rev., 2015, 44, 4494-4500.

18 J. Zhou, Z. Liu and F. Li, Chem. Soc. Rev., 2012, 41, 1323.

19 Q. Liu, Y. Sun, T. Yang, W. Feng, C. Li and F. Li, J. Am. Chem. Soc., 2011, 133, 17122-17125.

20 F. Wang, Y. Han, C. S. Lim, Y. Lu, J. Wang, J. Xu, H. Chen, C. Zhang, M. Hong and X. Liu, Nature, 2010, 463, 1061-1065.

21 E. M. Chan, Chem. Soc. Rev., 2015, 44, 1653-1679.

22 N. M. Idris, M. K. G. Jayakumar, A. Bansal and Y. Zhang, Chem. Soc. Rev., 2014, 44, 1449-1478.

23 A. Sedlmeier and H. H. Gorris, Chem. Soc. Rev., 2014, 44, 1526-1560.

24 M.-K. Tsang, G. Bai and J. Hao, Chem. Soc. Rev., 2015, 44, 1585-1607.

25 D. Yang, P. Ma, Z. Hou, Z. Cheng, C. Li and J. Lin, Chem. Soc. Rev., 2014, 44, 1416-1448.

26 W. Zheng, P. Huang, D. Tu, E. Ma, H. Zhu and X. Chen, Chem. Soc. Rev., 2014, 44, 1379-1415.

27 L. Prodi, E. Rampazzo, F. Rastrelli, A. Speghini and N. Zaccheroni, Chem. Soc. Rev., 2015, 44, 4922-4952.

28 H. Guo, Z. Li, H. Qian, Y. Hu and I. N. Muhammad, Nanotechnology, 2010, 21, 125602.

29 J. Jin, Y.-J. Gu, C. W.-Y. Man, J. Cheng, Z. Xu, Y. Zhang, H. Wang, V. H.-Y. Lee, S. H. Cheng and W.-T. Wong, ACS Nano, 2011, 5, 7838-7847.

30 G. Chen, T. Y. Ohulchanskyy, R. Kumar, H. Ågren and P. N. Prasad, ACS Nano, 2010, 4, 3163-3168.

31 Q. Cheng, J. Sui and W. Cai, Nanoscale, 2012, 4, 779.

32 F. Auzel, Chem. Rev., 2004, 104, 139-173.

33 F. Auzel, J. Lumin., 1990, 45, 341-345.

34 H. H. Gorris and O. S. Wolfbeis, Angew. Chem., 2013, 125, 3668-3686.

35 F. Wang and X. Liu, Chem. Soc. Rev., 2009, 38, 976-989.

36 X. Chen, D. Peng, Q. Ju and F. Wang, Chem. Soc. Rev., 2014, 44, 1318-1330.

37 L. Tu, X. Liu, F. Wu and H. Zhang, Chem. Soc. Rev., 2015, 44, 1331-1345.

38 G. Liu, Chem. Soc. Rev., 2014, 44, 1635-1652.

39 M. He, P. Huang, C. Zhang, H. Hu, C. Bao, G. Gao, R. He and D. Cui, Adv. Funct. Mater., 2011, 21, 4470-4477.

40 K. Gavvala, R. K. Koninti, A. Sengupta and P. Hazra, Phys. Chem. Chem. Phys., 2014, 16, 14953.

41 S. N. Lee, J. Park, M. Lim and T. Joo, Phys. Chem. Chem. Phys., 2014, 16, 9394.

42 A. Chatterjee and D. Seth, Photochem. Photobiol. Sci., 2013, 369-383.
43 T. Shanmugapriya, R. Vinayakan, K. G. Thomas and P. Ramamurthy, CrystEngComm, 2011, 13, 2340.

44 B. Carlotti, E. Benassi, A. Cesaretti, C. G. Fortuna, A. Spalletti, V. Barone and F. Elisei, Phys. Chem. Chem. Phys., 2015, 17, 20981-20989.

45 B. Carlotti, A. Cesaretti, C. G. Fortuna, A. Spalletti and F. Elisei, Phys. Chem. Chem. Phys., 2015, 17, 1877-1882.

46 F. Meng, S. Liu, Y. Wang, C. Tao, P. Xu, W. Guo, L. Shen, X. Zhang and S. Ruan, J. Mater. Chem., 2012, 22, 22382.

47 L. Wang, R. Yan, Z. Huo, L. Wang, J. Zeng, J. Bao, X. Wang, Q. Peng and Y. Li, Angew. Chem., Int. Ed., 2005, 44, 6054-6057.

48 L. Wang, X. Xue, H. Chen, D. Zhao and W. Qin, Chem. Phys. Lett., 2010, 485, 183-186.

49 H. Li and L. Y. Wang, Chin. Sci. Bull., 2013, 58, 4051-4056. 50 B. Voß, J. Nordmann, A. Uhl, R. Komban and M. Haase, Nanoscale, 2013, 5, 806-812.

51 R. Komban, J. P. Klare, B. Voss, J. J. Nordmann, H.-J. Steinhoff and M. Haase, Angew. Chem., Int. Ed., 2012, 51, 6506-6510.

52 Q. Tian, K. Tao, W. Li and K. Sun, J. Phys. Chem. C, 2011, 115, 22886-22892.

53 J. Shan and Y. Ju, Nanotechnology, 2009, 20, 275603.

54 J. Shan, M. Uddi, N. Yao and Y. Ju, Adv. Funct. Mater., 2010, 20, 3530-3537.

55 J. F. Suyver, J. Grimm, K. W. Krämer and H. U. Güdel, J. Lumin., 2005, 114, 53-59.

56 H. U. G. A. Shalav, B. S. Richards and K. W. Krämer, Conf. Rec. IEEE Photovoltaic Spec. Conf., 2005, 31, 114-117.

57 F. Vetrone, J. C. Boyer, J. A. Capobianco, A. Speghini and M. Bettinelli, J. Phys. Chem. B, 2003, 107, 1107-1112.

58 S. V. Eliseeva and J.-C. G. Bünzli, Chem. Soc. Rev., 2010, 39, 189-227.

59 J. M. F. van Dijk, J. Chem. Phys., 1983, 78, 5317.

60 J. Zhao, Z. Lu, Y. Yin, C. McRae, J. A. Piper, J. M. Dawes, D. Jin and E. M. Goldys, Nanoscale, 2013, 5, 944-952.

61 W. Yu, W. Xu, H. Song and S. Zhang, Dalton Trans., 2014, 43, 6139-6147.

62 R. Thoma, H. Insley and G. Hebert, Inorg. Chem., 1966, 1005, 1222-1229.

63 R. E. Thoma, C. F. Weaver, H. A. Friedman, H. Insley, L. A. Harris and H. A. Yakel, J. Phys. Chem., 1961, 65, 1096-1099.

64 K. W. Krämer, D. Biner, G. Frei, H. U. Güdel, M. P. Hehlen and S. R. Lüthi, Chem. Mater., 2004, 16, 1244-1251.

65 Y. Song, Q. Tian, R. Zou, Z. Chen, J. Yang and J. Hu, J. Alloys Compd., 2011, 509, 6539-6544.

66 S. Wilhelm, T. Hirsch, W. M. Patterson, E. Scheucher, T. Mayr and O. S. Wolfbeis, Theranostics, 2013, 3, 239-248.

67 J. F. F. Suyver, J. Grimm, M. K. K. van Veen, D. Biner, K. W. W. Krämer and H. U. U. Güdel, J. Lumin., 2006, 117, 1-12.

68 S. Schietinger, L. D. S. Menezes and O. Benson, Nano Lett., 2009, 9, 2477-2481.

69 S. Mishra, G. Ledoux, E. Jeanneau, S. Daniele and M.-F. Joubert, Dalton Trans., 2012, 41, 1490. 
70 M. Wang, G. Abbineni, A. Clevenger, C. Mao and S. Xu, Nanomed. Nanotechnol. Biol. Med., 2011, 7, 710-729.

71 Y. Chen, W. He, H. Wang, X. Hao, Y. Jiao, J. Lu and S. Yang, J. Lumin., 2012, 132, 2404-2408.

72 J. Shan, M. Uddi, R. Wei, N. Yao and Y. Ju, J. Phys. Chem. C, 2009, 114, 2452-2461.

73 D. Lu, S. K. Cho, S. Ahn, L. Brun, C. J. Summers and W. Park, ACS Nano, 2014, 7780-7792.

74 J. F. Suyver, A. Aebischer, S. García-Revilla, P. Gerner and H. U. Güdel, Phys. Rev. B: Condens. Matter Mater. Phys., 2005, 71, 1-9. 75 J. D. Kingsley, Appl. Phys. Lett., 1969, 15, 115.

76 J. L. Sommerdijk, J. Lumin., 1971, 4, 441-449.

77 A. Pandey, V. K. Rai, R. Dey and K. Kumar, Mater. Chem. Phys., 2013, 139, 483-488.

78 H. W. Song, H. P. Xia, B. J. Sun, S. Z. Lu, Z. X. Liu and L. X. Yu, Chin. Phys. Lett., 2006, 23, 474-477.
79 Y. Wang, L. Tu, J. Zhao and Y. Sun, J. Phys. Chem. C, 2009, 113, 7164-7169.

80 F. Liu, E. Ma, D. Chen, Y. Yu and Y. Wang, J. Phys. Chem. B, 2006, 110, 20843-20846.

81 J. Liao, L. Nie, S. Liu, B. Liu and H. Wen, J. Mater. Sci., 2014, 49, 6081-6086.

82 L. Lei, D. Chen, W. Zhu, J. Xu and Y. Wang, Chem. - Asian J., 2014, 9, 2765-2770.

83 X. Bai, H. Song, G. Pan, Y. Lei, T. Wang, X. Ren, S. Lu, B. Dong, Q. Dai and L. Fan, J. Phys. Chem. C, 2007, 111, 13611-13617.

84 J. D. Suter, N. Pekas, M. T. Berry and P. S. May, J. Phys. Chem. C, 2014, 118, 13238-13247.

85 S. Wilhelm, M. Kaiser, C. Würth, J. Heiland, C. CarrilloCarrion, V. Muhr, O. S. Wolfbeis, W. J. Parak, U. ReschGenger and T. Hirsch, Nanoscale, 2015, 7, 1403-1410. 